\title{
THE WINGS OF THE REMARKABLE ARCHAIC MECOPTERON NOTIOTHAUMA REEDI MCLACHLAN WITH REMARKS ON THEIR PROTOBLATTOID AFFINITIES
}

\author{
By G. C. Crampton, Ph. D.
}

Massachusetts Agricultural College, Amherst, Mass.

Through the great generosity of Dr. Edwyn P. Reed, the distinguished Chilean surgeon, I have had the privilege of making an anatomical study of the remarkable archaic Mecopteron Notiothauma reedi, McLachlan. In presenting me with the only known specimen of the hitherto undescribed male of Notiothauma for dissection and description, Dr. Reed has placed me deeply in his debt, and I would use this opportunity of thanking Dr. Reed for the rare privilege of studying this unique specimen.

The male of Notiothauma conforms to the general description of the female in having a castaneous body, but the wings of the male, and those from a specimen which had been damaged by pests (presumably a female, though the sex could not be determined from the remaining fragments) are ochreous, shot through with brown, giving a "brindled" appearance to the incumbent wings.

The male has a remarkable median dorsal process on what appears to be the fourth abdominal tergite (the specimen has not yet been softened for study) and on the next tergite is a pair of rather small lateral tergal processes, while the tergite behind this bears a pair of longer lateral tergal processes, which give a remarkable appearance to the flattened abdomen. The abdomen does not taper like that of a typical Panorpid, and is somewhat suggestive of the abdomen of the Mecopteron Merope, which is rather closely allied to Notiothauma. 
The genitalia are rather "bulbous" and the basistyles or basal segments of the claspers of the male are rather short and stout; and the dististyles or distal segments of the claspers, unlike those of Merope (which has long slender dististyles) are shorter and stouter, and are somewhat furcate, with the exterior terminal branch curving outward (laterad) to some extent, apparently for the purpose of lying on either side of the median dorsal process (described above) when the genitalia are held forward in repose.

I would designate this hitherto undescribed male as the allotype of Notiothauma reedi, McLachlan, and a detailed description of it will be presented in a later paper dealing with the morphology of this remarkable Mecopteron, which is the only scorpionfly with flat incumbent wings (see Plate 2).

There is no fundamental difference between the wings of the male and those of the damaged specimen (presumably a female), so that the accompanying description of the wings of the supposed female will serve to illustrate the later description of the venation of the male, in describing the alar ossicles and other features of the basal region of the wing, in discussing the morphology of the male insect.

The measurements of the wings are as follows: Length of fore wing, $23.5 \mathrm{~mm}$.; greatest width of fore wing, 10 $\mathrm{mm}$.; length of hind wing, $22 \mathrm{~mm}$.; greatest width of hind wing, $9 \mathrm{~mm}$. The fore wings are more deeply pigmented and are ochreous, while the hind wings are more hyaline, and have a yellow tinge. The fore wings are like delicate tegmina, apparently derived from Protoblattoid (Protoblattid-like) or Protorthopteroid (Protorthoptera-like) prototypes, but the hind wings have lost the anal fan characteristic of the Protoblattids, etc., as likewise have the Isoptera (except Mastotermes), for that matter, which are the direct descendants of Protoblattoid forbears. The fore wings are somewhat broader in the distal half of the wing, and are broadly rounded apically, resembling in these respects the fore wings of the Protoblattids Asyncritus, Adiphlebia, etc., figured by Handlirsch, 1925 (Schroeder's "Handbuch," Band 3), or the Protorthopteroid insect Metropator, figured by Handlirsch, 1909 (Die Fossile Insekten). These are Protoblattoid features pointing to a 
Protoblattoid ancestry for the Mecoptera, instead of indicating an ancestry for the Mecoptera in forms like the Megasecoptera or even the Palæodictyoptera.

The Megasecoptera and Palæodictyoptera are Archipterygota, or insects incapable of folding the wings along the abdomen in repose, while the Protoblattids and Protorthoptera are Neopterygota, or insects capable of laying the wings along the abdomen in repose, and the Protoblattids and Blattids typically hold the wings in the recumbent position in repose (i. e., the wings laid flat, one on top of the other, on the top of the abdomen) and it is a very significant fact that Notiothauma holds its wings in the incumbent position in repose, so that this archaic Mecopteron must have been descended from Neopterygotan ancestors rather than from Archipterygotan ancestors such as the Megasecoptera, etc., regarded by Handlirsch and Tillyard as the ancestors of the Mecoptera. (See Plate 3)

The basal arch ( $b a$ of Figs. 1 and 7 ) of the first anal vein, forming a typical "basoplica," together with the foldlike depression, like that described by Crampton, 1927 (Psyche, 34, p. 59) and 1928 (Bull. Brooklyn Ent. Soc., 23, p. 113) in the Blattids, Isoptera, Orthoptera, Cicadas, Trichoptera, etc., which have developed these structures in connection with laying the wings along the abdomen in repose, likewise indicates a Neopterygotan ancestry for the Mecoptera.

The formation of cellules in the wings of the Protoblattids Asyncritus, Adiphlebia, etc., suggests the beginnings of a tendency to form cellules in the fore wings-a tendency which has been carried to an extreme in Notiothauma. It should be noted that it is not necessary for all of the Protoblattids or for all of the Mecoptera to exhibit this tendency in order to derive the Mecoptera from a Protoblattoid ancestory, since, according to the adumbration theory, some members of an ancestral group may exhibit tendencies which later reappear in some members of a derived group without these features being exhibited by all, or most, of the members of either group, as has been discussed elsewhere. It is therefore illogical to demand that all of the Protoblattoids shall exhibit a tendency toward the formation of numerous cellules, in order to derive such a 
Mecopteron as Notiothauma (with its many cellules) from Protoblattoid ancestors.

In both the fore and hind wings of Notiothauma, there is a postero-basal lobe, or jugalula, labelled $a$ in Figs. 1 and 2, which is called the alula in Coleoptera, etc., but the term alula was long ago used by Osten-Sacken, 1896 (Berlin Ent. Zeit., 41, p. 285) to designate an entirely different structure, namely the anal lobe of the Dipterous wing (i. e., the lobe distal to the calypteres) ; and it is preferable to refer to the jugalular lobe as the jugalula, since it is homologous with the jugalula of the roach. Esben-Petersen, 1921 (Mecoptera in Coll. Zool. Selys Longchamps) calls these jugalulæ the "clavi" in Notiothauma, but the clavus is an entirely different region, homologous with the anal region presently to be described, and there is no excuse for applying the term clavus to any structure other than the region homologous with the clavus of the Hemiptera. The jugalula $a$ is bordered by a fringe of hairs labelled $a f$ in Figs. 1 and 2, and when the jugalula $a$ of the fore wing (Fig. 1) is folded forward under the fore wing, it engages the bristles labelled $b s c$ in Fig. 2 of the hind wing, thus serving as a primitive type of jugum. In my specimens, the jugalula was folded forward, and it was very difficult to make out its structure in the mounted wings.

The basicostal bristles bcs of Figs. 1 and 2, are borne on a thickened, antero-basal, marginal structure in both wings; and these bristles in the hind wing are apparently the forerunners of the frenulum of higher insects, although they can hardly be called a frenulum on the fore wing. These bristles are unusually stout and long, and belong to the type of bristle which may be called dinotrichia, or powerful bristles, such as those occurring on the veins, etc., at the base of the fore wings (Fig. 7) or on the thorax, etc., Macrotrichia occur on the costal margin of the wings in the neighborhood of the humeral veinlet $h$ of Figs. 1 and 2 , and gradually become smaller toward the middle of the wing, (they are not drawn in this region of the wing in Figs. 1 and 2). The "dinotrichia" occurring on some of the veins in the basal region of the fore wing are shown in Fig. 7, and the sockets or pits, which are left when such bristles are broken off, are shown in the figure. Macro- 
trichia occur on the ventral surface of the basicostal structure labelled $b c$ in Fig. 4, and on the ventral surface of the humeral veinlet $h$ of Fig. 4 ; and a row of macrotrichia occurs on the ventral surface of the subcostal vein shown in Fig. 4. This row of macrotrichia may aid in holding the wings in place in repose.

Forbes, 1924 (Ent. News, 35, p. 232) in describing the nygmata of Holometabolous insects, states that in "Merope and apparently Notiothauma nygmata are absent," but I find in the basal costal cell, for example, what appears to be the homologue of a nygma, similarly located to that of Panorpodes (see $n$ of Fig. 7), and nygmata are thus apparently present in the fore wings of Notiothauma, although I have not examined Merope to determine if they are present in this insect also.

The venation of the hind wings is quite easily homologized, but the tangle of cellules in the distal portion of the fore wings makes it extremely difficult to trace the course of the veins in this region of the fore wings, so that the course of the distal portions of such veins as the second, third and fourth branches of Media is merely suggested, although the basal portions of these veins are quite easily homologized.

The fore wing has preserved a suggestion of a humeral lobe in the curved contour of the basal portion of the wing just anterior to the label $h$ in Fig. 1 (which is a Protoblattoid or Protorthopteroid feature) and the costal vein has become interrupted just basad of the humeral veinlet $h$ of Fig. 1. The detached basal portion of the vein becomes broadened (to accommodate the large bristles $b s c$ ) and forms a structure homologous with the sclerite called the basicosta in the roach, Mantids, Trichoptera, Cicadas, etc. (Psyche, 34, p. 59, and Bull. Brooklyn Ent. Soc., 23, p. 113). The occurrence of such a basicostal sclerite in Notiothauma indicates that its fore wing was derived from a Blattoid or Protoblattoid prototype rather than from a wing of the type occurring in the Archipterygotan insects (which have no such sclerite). I find a trace of the basicostal sclerite even in the hind wing of such a highly specialized insect as the monarch butterfly Danaus archippus ("Anosia plexippus") in which the costal vein fades out 
and the humeral veinlet is retained to support the weakened humeral lobe. In the hind wing of Malacosoma and other Lasiocampids there are two veinlets called the humeral cross veins by Comstock, 1924 (An Introduction to Entomology) but I think it preferable to restrict the term humeral veinlet to the first veinlet $h$ of Figs. 1 and 7, and to refer to the one distad of it as the posthumeral veinlet (i. e., ph. of Fig. 7). These structures are referred to as veinlets rather than as cross-veins, since they are homologous with the veinlets of the Neuroptera, etc. The humeral veinlet $h$ of Figs. 1 and 7, is much stouter than the other veinlets; and the weaker posthumeral veinlet $p h$ is more pronouncedly curved.

The veinlets in the broad costal area of the fore wing have branched or are connected by cross veins in an irregular fashion causing a distortion of the veinlets and producing numerous cellules, which are irregularly pentagonal or hexagonal in the basal region and are more elongated and subquadrate in the distal region of the costal area. The broad costal area apparently represents a condition inherited from Protoblattoid ancestors resembling Asyncritus in some respects, and the curve in the costal margin of the fore wing may also represent the retention of a tendency more markedly developed in the Protoblattoid insects, instead of these features representing a type of specialization peculiar to Notiothauma.

As is true of Mecoptera in general, the subcostal vein $S c$ of the fore wing (Figs. 1 and 7 ) is a concave vein, and a minus sign (-) has been placed above it in Figs. 1 and 7, to indicate this fact. The base of $S c$ dips below the base of the radius $R$, as is indicated in Fig. 7. After paralleling $R$ for some distance, $S c$ ends at the pterostigma pst of Fig. 1, although some of the branches of $S c$ appear to penetrate the pterostigma for a short distance. The wide separation of $S c$ from the costal margin, and its paralleling $\mathrm{R}$ for such a considerable distance are Protoblattoid features apparently inherited from a Protoblattoid ancestry.

The radial vein $R$ is higher than the concave vein Sc, and appears to have much the same character as that of $R_{1}$ which is a convex vein, so that $R$ may be regarded as a convex vein, although its sector $R_{\mathrm{s}}$ seems to be a concave 
vein. $R$ fuses with $M$ basally, and is contiguous with $M$ until it forks-or rather, the space between $R$ and $M$ is sclerotized giving the appearance of a union between the two veins, although the veins themselves are not as closely contiguous as this pigmentation or sclerotization of the intervening membrane would suggest (See Fig. 7). $\mathbf{R}_{\mathrm{s}}$ is given off in the basal fifth of the wing, and is richly branched, being somewhat like the radial sector of the Protoblattid Stenoneura in this respect, though it is of course much more like the venation of such primitive fossil Mecoptera as "Protomerope," or the primitive fossil Neuropteron Permorapisma (particularly the latter) than it is like the Protoblattids, since the Mecoptera and Neuroptera are naturally more closely related to Notiothauma than the Protoblattids are. The convex vein $R_{1}$ is apparently unbranched and extends distally below the pterostigma pst almost to the margin of the wing, although a short backward extension of the pterostigma in this region intervenes between the margin of the wing and the tip of $R_{1}$. The concave radial sector $R_{\mathrm{s}}$ is given off in the basal fifth of the wing, and is richly branched with numerous cellules between the distal portions of its branches, and the cellules tend to become elongated and more quadrilateral than the cellules of the costal or cubital regions. It is quite easy to trace the branching of the radial sector, and the branching of its forks into $R_{2}$ and $R_{3}$ or into $R_{4}$ and $R_{5}$, in the basal portion of the wing, but the tracing of the courses of these branches in the distal portion of the wing is not as easy a matter as it is in such forms as Merope or even Permorapisma, due to the fact that the course of these branches is obscured by the tangle of cellules in Notiothauma, and on this account the interpretation of the branches of radius in the figure of the fore wing is purely tentative, although in the hind wing of Notiothauma the course of these branches can be followed with ease.

$M$ seems to be a concave vein, although it fuses with $R$ basally and is contiguous with $R$ in the basal region of the wing. The branches of $M$ are also concave veins, so that it should be an easy matter to distinguish the course of these veins from that of $\mathrm{Cu}_{1}$ which is a convex vein, but 
the course of the median veins is so extremely aberrant, that I am the least confident of my interpretations in this region of the fore wing, although of course it is an easy matter to interpret the median veins of the hind wing. I have figured the median veins of the wings of Notiothauma from all available sources, using the original photograph (which is much clearer than the published figure) from which the illustration of Dr. C. E. Porter's note on Notiothauma was made (Revista Chileana Hist. Nat., 1929, XXXIII, p. 288),-Dr. Porter having very kindly sent me the original photograph-and I have also used EsbenPetersen's figure of the wings of Notiothauma, but even with these figures to aid me, in addition to examining the wings of two specimens of Notiothauma, I am not very sure of the course of the branches of $\mathrm{M}$ in the fore wing! In his review of Imms' book, Tillyard, 1926 (N. Z. Jour. of Science and Technology, 8, p. 127) states that the "thyridium is a hyaline area on M just before it forks" in Trichopterous wings, and there is a clear spot at the forking of $M$ in Nannochorista, Sisyra, etc. Since there is a hyaline area (resembling the so-called bullæ) labelled $b$ in Figs 1, 3, 4, 5 and 6 at the base of what Esben-Petersen (1. c.) considers as the first fork of $M$ in the fore wing of Notiothauma, I feel almost certain that the forking of M is at the point labelled $b$ in these figures. This interpretation, however, would leave a whole vein unaccounted for (can this be $\mathrm{M}_{5}$ ?) but lying between the concave anterior branch of $\mathrm{M}$ and the convex anterior branch of $\mathrm{Cu}$ (i. e., $\mathrm{Cu}_{1}$, whose course is indicated by a + sign in Fig 1 ) in these figures. Unlike the typically short $M_{5}$ of most insects (although $\mathrm{M}_{5}$ is longer in some Psychopsidæ), the vein in question is of considerable extent, and joins the rest of the branches of $\mathrm{M}$ instead of extending across to $\mathrm{Cu}_{1}$ as the vein $\mathrm{M}_{5}$ usually does, and as is done by the vein labelled $\mathrm{M}_{5}$ in Fig. 1, etc. I am therefore inclined, purely provisionally, to interpret as the first forking of $M$, the fork which is located just distad of the dotted line running up from the label $M$ in Fig. 1. This fork occurs in all of the wings, and figures of wings, which $I$ have seen; so it can hardly be an added cross vein that has taken on the appearance of a fork in one specimen: furthermore, it is continued 
in the vein labelled $M_{3}$ in Fig. 1-although it may possibly continue on down and fuse with $\mathrm{Cu}_{1}$ instead, but the latter view is not very probable (although it should be considered as a possibility), because it would leave the vein labelled $\mathrm{M}_{3}$ unaccounted for. I am therefore inclined purely provisionally to interpret the fork of $M$ just distad of the dotted line running up from the label IM in Fig. 1 as the forking of $\mathrm{M}$ into $\mathrm{M}_{1+2}$ and $\mathrm{M}_{3+4}$ as is indicated by the labelling. The fork at the hyaline spot labelled $b$ in Figs. $1,3,4,5$ and 6 , would then be the forking of $\mathrm{M}_{1+2}$ into $\mathrm{M}_{1}$ and $\mathrm{M}_{2}$. Where the forking of $\mathrm{M}_{3+4}$ into $\mathrm{M}_{3}$ and $\mathrm{M}_{4}$ is, $\mathrm{I}$ do not know, although I am inclined to think that it may be just basad of the dotted line running up from the label $\mathrm{M}_{3}$ in Fig. 1. If this be correct, $\mathrm{M}_{3}$ would be the vein so labelled in the Figure, while $\mathrm{M}_{4}$ would be the short vein extending to and fusing with $\mathrm{Cu}_{1}$ in Fig. 1. On the other hand, this short vein may be merely a cross vein between vein $\mathrm{M}_{3+4}$ and $\mathrm{Cu}_{1}$, in which case the vein labelled $\mathrm{M}_{3}$ in Fig. 1 would in reality be vein $\mathrm{M}_{3+4}$. $I$ have provisionally followed the former view and have labelled the median veins as though $\mathrm{M}_{4}$ had fused with $\mathrm{Cu}_{1}$ in Fig. 1 . There is such a disconcerting tangle of cellules (which are more elongate and quadrangular in the medial region than in the cubital region) in the medial region, however, that I would not insist on the interpretation of the courses of the branches of $M$ indicated by the labelling, and the final interpretation of these veins must await the study of the pupal tracheation, or the comparison with some less complicated venation in the fore wing of some as yet unknown Mecopteron. Merope and "Protomerope," however (both of which are related to Notiothauma) are primitive Mecoptera with a less complicated venation which shows no indication of a fusion of $\mathrm{M}_{4}$ with $\mathrm{Cu}_{1}$, and this fact makes me suspect that the vein labelled $M_{3}$ in Fig. 1 is in reality vein $M_{3+4}$ and the forking of this vein into $\mathrm{M}_{3}$ and $\mathrm{M}_{4}$ occurs further out toward the distal half of the wing, and the labels should therefore be shifted accordingly in Fig. 1. The development of the medial field is much greater in Notiothauma than in most Protoblattids, but some of the Protoblattids, such as Eucaenus, have a four branched media such as the ancestors of the Mecoptera must have had. 
The cubital field of Notiothauma is filled with broader irregular. pentagonal or hexagonal cellules and the cubital field is remarkably like that of such Protoblattids as Asyncrytus. The extremely short basal portion of $\mathrm{Cu}$ (i. e., before it forks) is another feature strongly suggestive of these Protoblattids, and is an added feature pointing to a Protoblattoid ancestry for Notiothauma (and hence for the Holometabola in general). As was mentioned above, $\mathrm{Cu}_{1}$ is a convex vein (as is indicated by a $+\operatorname{sign}$ in Fig. 1) and $\mathrm{Cu}_{2}$ is a concave vein (indicated by a - sign in Fig. 1), and this seems to be characteristic of all Mecoptera. As occurs in the wings of some fossil, but no other Mecoptera, $\mathrm{Cu}_{1}$ branches into $\mathrm{Cu}_{1}$ a and $\mathrm{Cu}_{1} \mathrm{~b}$ judging from the condition exhibited by the hind wing, but I am not certain where this occurs in the fore wing unless it be at or just beyond the point where the dotted line running up from the label $M_{1}$ in Fig. 1 crosses $\mathrm{Cu}_{1}$. As is also true of the Mecopteron Panorpodes, a nygma or wing spot, occurs in the basal cubital cell, as is shown in Fig. 7, where the nygma is labelled $n$. Just behind $\mathrm{Cu}$ is the preclaval rima or cracklike line demarking the anterior limits of the claval or anal area. This crack frequently interrupts the basal portion of $\mathrm{Cu}$, and may have been formed in connection with the developing ability to lay the wings back in the incumbent position.

The anal or claval area (i. e., the clavus of Hemiptera) extends from the above-mentioned claval rima to the jugalula labelled $a$ in Fig. 1, and contains the three anal veins which are convex veins in Mecoptera in general. The first anal, labelled 1. A. in Fig. 1, has a well developed basal arch labelled $b a$ which occurs as a basal ridge, with an accompanying pocket or fold developed in connection with the ability to lay the wings back along the abdomen in repose. The weakening of the costal margin and the consequent detachment of the basicostal sclerite or protuberance $b c$ of Fig. 1, is probably also developed in connection with the folding of the wings along the abdomen in repose, so that all of these features are of importance from the phylogenetic standpoint, and it is surprising that no one has referred to such features in the wings of insects. I have found them in the Blattids, Isoptera, Cicadas, 
Gryllacridæ, Panorpids, etc. (Psyche, 34, p. 59 and Bull. Brooklyn Ent. Snc., 23, p. 113), and when such an important form as the fossil Metropator is figured with a basal arch in the first anal vein by Tillyard, 1926 (Amer. Jour. of Science, 11, p. 161) I think that this (together with the outline, venation, etc. of the wing) indicates that Metropator is more closely related to the Protorthopteroids than to the Palaeodictyoptera, although Handlirsch places Metropator in his order Palaeodictyoptera, and not in the order Protorthoptera as Tillyard states. Eubleptus (order Eubleptoptera) may be nearer the Palaeodictyoptera, but Metropator (Metropatoroptera) evidently represents a type worthy of ordinal rank, closely related to the Protorthoptera, and with a venation approaching that of some Mecoptera with reduced venation, through convergence. Metropator lacks the costal veinlets, the forked $\mathrm{Cu}_{1}$ and other features which were undoubtedly present in the ancestral Mecoptera, and I think that Tillyard, 1926, is mistaken in considering this Protorthopteroid insect as an ancestral Mecopteron.

The resemblance of the wing of Metropator to that of a Mecopteron with reduced venation, is apparently due to convergence, or possibly to adumbration and the relationship of Metropator to the Mecoptera would be by way of a common Protorthopteroid or Protoblattoid ancestor, and would not be the direct relationship of ancestral and derived types.

As was mentioned above, the first anal has a well developed basal arch. The second anal is not so pronouncedly arched, and joins the third anal basally. The third anal has an almost straight trunk (anotruncus) which gives off four branches unilaterally-though some of these may be branches of the second anal vein. The cellules filling the anal or claval area make it very difficult to determine the course of the anals and their branches, and the interpretation here given is truly provisional. The trunk of the third anal demarks the claval or anal area from the jugalula $a$ of Fig. 1 in many insects, and is a fairly serviceable landmark in Notiothauma.

Esben-Petersen refers to the jugalula $a$ of Fig. 1, as the "clavus," but this lobe is not the homologue of the clavus 
of the Hemiptera, etc., and should not be designated as such. This lobe is homologous with the so-called alula of Coleoptera, etc., but the term alula was applied to the anal lobe of the Dipterous wing by Osten-Sacken, 1896, as was mentioned above, and since the jugum is formed in this region, it is preferable to refer to it as the jugalula, as in the case of the homologous structure in the roach and other insects (Isoptera, etc., described in Bull. Brooklyn Ent. Soc., 23, p. 113 and Psyche, 34, p. 59). The veins in the lobe labelled $a$ in Fig. 1 may be called the axillary or postanal veins. They serve to strengthen the lobe when it is used as a jugum, as is the case in the fore wing of Notiothauma. They are apparently absent in the hind wing, since the lobe is not used as a jugum in this wing. The elongated sclerite just below the label $b a$ in the lobe of the fore wing (Fig. 1) is probably the homologue of the alar ossicle called the basanale in the roach, etc. (paper cited above). The jugalular lobe $a$ of Figs. 1 and 2 is bordered by the axillary cord or ligamentum, which bears a fringe of hairs labelled $a f$ in Figs. 1 and 2.

Since the venation of the hind wing is comparatively simple, it will not be necessary to discuss each of the veins in detail, and the labelling of the wing will be sufficient to indicate the homologies of the veins. There are a few points, however, which merit separate consideration in comparing the two wings.

The hind wing is somewhat shorter and narrower than the fore wing in actual millimeters, but in proportion to its length, the hind wing is a little broader (proportionately) than the fore wing, and is a little narrower at its base than the fore wing is. Its jugalular lobe $a$ (Fig. 2) is likewise somewhat weaker than the corresponding lobe of the fore wing ( $a$ of Fig. 1).

The hind wing has no such pronounced curve in the costal margin beyond the humeral veinlet $h$ (Fig. 2) as occurs in the fore wing (Fig. 1), and the cellules in the costal region of the hind wing are less numerous than in this region of the fore wing. The costal veinlets of the hind wing are more "normal" or regular; and the costal space is not so broad in the hind wing as it is in the fore wing. The cross veins of the hind wing, like those of the fore 
wing, are frequently broken by "pellucidæ" (maculæ pellucidæ) or "bullæ," which are clear spots. Their true function is not definitely known. Only a few of these are indicated in the figures.

The cellules of the hind wing are not as irregular as those of the fore wing, and the venation of the hind wing is more "normal" than that of the fore wing, particularly in the medial field. $M_{5}$ is not labelled in Fig. 2, but it can be identified by the dotted line running up from $\mathrm{M}_{3+4}$, which crosses $\mathrm{M}_{5}$. Since $\mathrm{M}_{4}$ is not fused with $\mathrm{Cu}_{1}$ in the hind wing, $\mathrm{I}$ am inclined to think that it is not fused with $\mathrm{Cu}_{1}$ in the fore wing either, so that the vein labelled $M_{3}$ in the fore wing is probably $\mathrm{M}_{3+4}$.

The stem of $\mathrm{Cu}$ is extremely short in the hind wing (Fig. 2) and its fork looks more like a cross vein than a fork. $\mathrm{Cu}_{1}$ is not united with $\mathrm{M}$, and it forks into $\mathrm{Cu}_{1}$ a and $\mathrm{Cu}_{1} \mathrm{~b}$, which is a very primitive feature not retained in other living Mecoptera, and the character of $\mathrm{Cu}$, with its short stem, is suggestive of a Protoblattoid origin.

The first anal vein of the hind wing is not markedly curved at its base, and the second anal vein parallels it rather closely. The trunk of the third anal gives off three branches anteriorly (unilaterally) which leads me to think that the third anal of the fore wing branches in the same fashion. The fact that the anals exhibit no tendency to loop up as they do in the fore wings of certain Trichoptera, etc., shows that Notiothauma is a rather primitive Holometabolan, and its venation and wing characters indicate that it is one of the most primitive members of the order Mecoptera.

In referring to the "Protoblattoid" or "Protorthopteroid" ancestors of higher insects, it should be borne in mind that the Protoblattids and Protorthoptera are fundamentally alike, and the division into these two groups is one of convenience rather than a division into groups of ordinal rank, since the Protoblattids and Protorthoptera intergrade so markedly that it is doubtful that they represent groups of more than subordinal rank. Since the two groups thus intergrade, the terms "Protoblattoid" and "Protorthopteroid" are practically interchangeable because the Protoblattids are in reality "Protorthopteroid" or Protorthop- 
tera-like, and the Protorthoptera are in reality "Protoblattoid" or Protoblattid-like, and it would be correct to state that the ancestors of the Mecoptera and other Holometabola were either Protorthopteroid or Protoblattoid; but since the Protoblattids are a little nearer the common stem forms from which the others were derived, it is somewhat more accurate to describe the ancestors of the Holometabola, etc., as "Protoblattoid." A study of the wings of such a primitive Mecopteron as Notiothauma very clearly indicates that the ancestors of the Mecoptera had (1) delicate tegmina, (2) wings which were broader in the distal half of the wing and were (3) broadly rounded apically. The wings were (4) incumbent in repose, and, to facilitate laying the wings back in repose, had developed (5) a break in the basal costal region, resulting in the formation of (6) a basicostal sclerite demarked from the rest of the costal vein, (7) a basal arch of the first anal vein with an accompanying (8) basal pocket or fold, and (9) a preclaval rima or crack which traverses the base of the cubital vein and aids in permitting the wing to be laid back in repose. (10) The costal area was very wide, and (11) cellules tended to develop in it. (12) The stem of $\mathrm{Cu}^{1}$ was very short and (13) irregular cellules filled the cubital area. (14) The fore wings bore a jugalular lobe. Most of these features occur in the Protoblattids, and in many of their living representatives, the Blattids (indeed, some entomologists do not recognize the Protoblattids as an order distinct from the Blattids); but these features are not characteristic of the Megasecoptera and other forms which have been proposed as the types ancestral to the Mecoptera. I would therefore maintain that the ancestors of the Mecoptera were Protoblattoid, and from such ancestors arose all of the lower Holometabola-and in fact of the Hemipteroid insects as well.

The types intermediate between the Protoblattoids and the ancestral Mecoptera are as yet unknown, but the immediate ancestors of the Mecoptera must have been extremely like those of the fossil Neuropteron Permorapisma, although the wings of Permorapisma itself, are not rounded

${ }^{1} \mathrm{Cu}_{1}$ was probably forked in the ancestral Mecoptera. 
apically (see figure by Tillyard, 1926, Proc. Linn. Soc. N. S. W., 51, p. 278). In the American Journal of Science, 11, p. 133, Tillyard, 1926, proposes that the fossil Mecopteron, which he calls "Protomerope," is ancestral to Merope and probably also to Notiothauma, but the shape of the wing of "Protomerope" is different from that of Notiothauma, the anals are not as primitive as those of Notiothauma, the first branch of $\mathrm{Cu}$ (i. e., $\mathrm{Cu}_{1}$ ) is not forked as in Notiothauma (which is a very primitive feature in Notiothauma) ; and many other features prevent our deriving Notiothauma from "Protomerope," which is more specialized in these respects than Notiothauma is. Under these conditions all that can be said of the hypothetical "Protonotiothaumidæ" ancestral to the Notiothaumidæ and Meropidæ, is that they were Protomecoptera, in which suborder the superfamily Meropoidea, including the Meropidæ and Notiothaumidæ, belongs.

The family Choristidæ (superfamily Choristoidea), which occupies a position at the base of the suborder Eumecoptera, may be descended from the fossil Permopanorpidæ, but the Choristidæ themselves, are so primitive in many respects, that they probably arose from forms more primitive than the Permopanorpidæ, and of a type almost as primitive as the ancestors of the Notiothaumidæ.

The Nannochoristidæ (superfamily Nannochoristoidea) possibly descended from the fossil Mesochoristidæ. There are several features, however, which suggest that the Nannochoristidæ and Panorpodidæ (Panorpodes) may have descended from ancestors resembling those of the fossil Mesopanorpidæ, and the shortened head in Nannochorista and Panorpodes may be a feature of some phylogenetic significance.

The Panorpidæ (superfamily Panorpoidea) were probably descended from the fossil Orthophlebiidæ. The Boreidæ (superfamily Boreoidea) were apparently descended from ancestors like the Panorpidæ. The Boreidæ, however, have an entirely different type of terminal abdominal structures (in both males and females) from those of the Panorpidæ, and the Boreidæ have become so extremely specialized that they might be placed in a distinct suborder, the Neomecoptera, distinct from the Eumecoptera, mentioned above. 
The Bittacidæ (superfamily Bittacoidea) are quite different from the rest of the Mecoptera in the character of the terminal abdominal structures of the male and female, and their slender bodies are modified along lines leading away from the typical scorpionfly trends. I, therefore, have no hesitancy in placing them in a distinct suborder, the Metamecoptera. The origin of these insects is obscure, although there is some evidence that they might have descended from the same ancestors from which the fossil Neorthophlebiidæ, were derived. It is more probable, however, that the Bittacidæ were derived from ancestors resembling those of the Panorpidæ. In the character of the male genitalia, the Choristidæ suggest the origin of the peculiar type occurring in the Bittacasidæ, and this might be taken to indicate a common ancestry for the Choristidæ and Bittacasidæ. The terminal structures of the female, however, would not bear this out, and until more is known of the comparative anatomy of the Mecoptera, it will be impossible to determine what family is the most closely related to the Bittacidæ, which occupy a rather isolated position in the order Mecoptera.

The terminal abdominal structure of the female Mecoptera have been figured in the December, 1928, issue of the Journal of the N. Y. Entomological Society, and the features referred to above are shown in this paper. The genitalia of the males of the Mecoptera referred to above are shown in a paper published in the Trans. of the American Ent. Society, 1923, 48, p. 207. The terminal structures of related Mecoptera will be discussed in the paper dealing with the male of Notiothauma, in which the anatomical features of the allotype will be shown in detail.

\section{Abbreviations}

A. Anal veins.

a. Jugalula or "alula," containing the axillary veins.

af. Alafimbrium or alular fringe.

b. Bullae or "pellucidae."

ba. Basarcus, or basal arch of the first anal vein.

bc. Basicosta.

bcs. Basicostal bristle.s 
C. Costal vein.

cs. Costal rima or suture.

$\mathrm{Cu}$. Cubital veins.

ds. Dinotrichia or powerful bristles.

h. Humeral veinlet.

M. Medial veins.

n. Nygma.

ph. Posthumeral veinlet.

pst. Pterostigma.

R. Radial veins.

s. Sockets of bristles.

Sc. Subcostal vein.

Explanation of Plates 2, 3, 4 and 5.

Fig. 1. Fore wing of Notiothauma (female).

Fig. 2. Hind wing of same.

Fig. 3. Veins of fore wing, from photograph by Dr. Porter.

Fig. 4. Ventral view of veins of fore wing.

Fig. 5. Veins of fore wing of male allotype.

Fig. 6. Veins of fore wing from figure by Esben-Petersen. Fig. 7. Enlarged view of basal portion of fore wing of female.

Plate 2 shows a lateral and a dorsal view of the allotype, male, of Notiothauma reedi, McL., from photographs made by Professor Davis, of the Department of Botany, M. A. C. In these photographs the Blattoid appearance of Notiothauma is well shown. Note particularly the flat incumbent wings, which are unlike those of any other living Mecopteron, in this respect. The figures of Notiothauma, with wings outstretched, do not give a correct idea of the remarkable appearance of this peculiar insect, as may be seen by comparing them with the photographs here given. The photographs are larger than "life size," in order to show the intricate venation. 


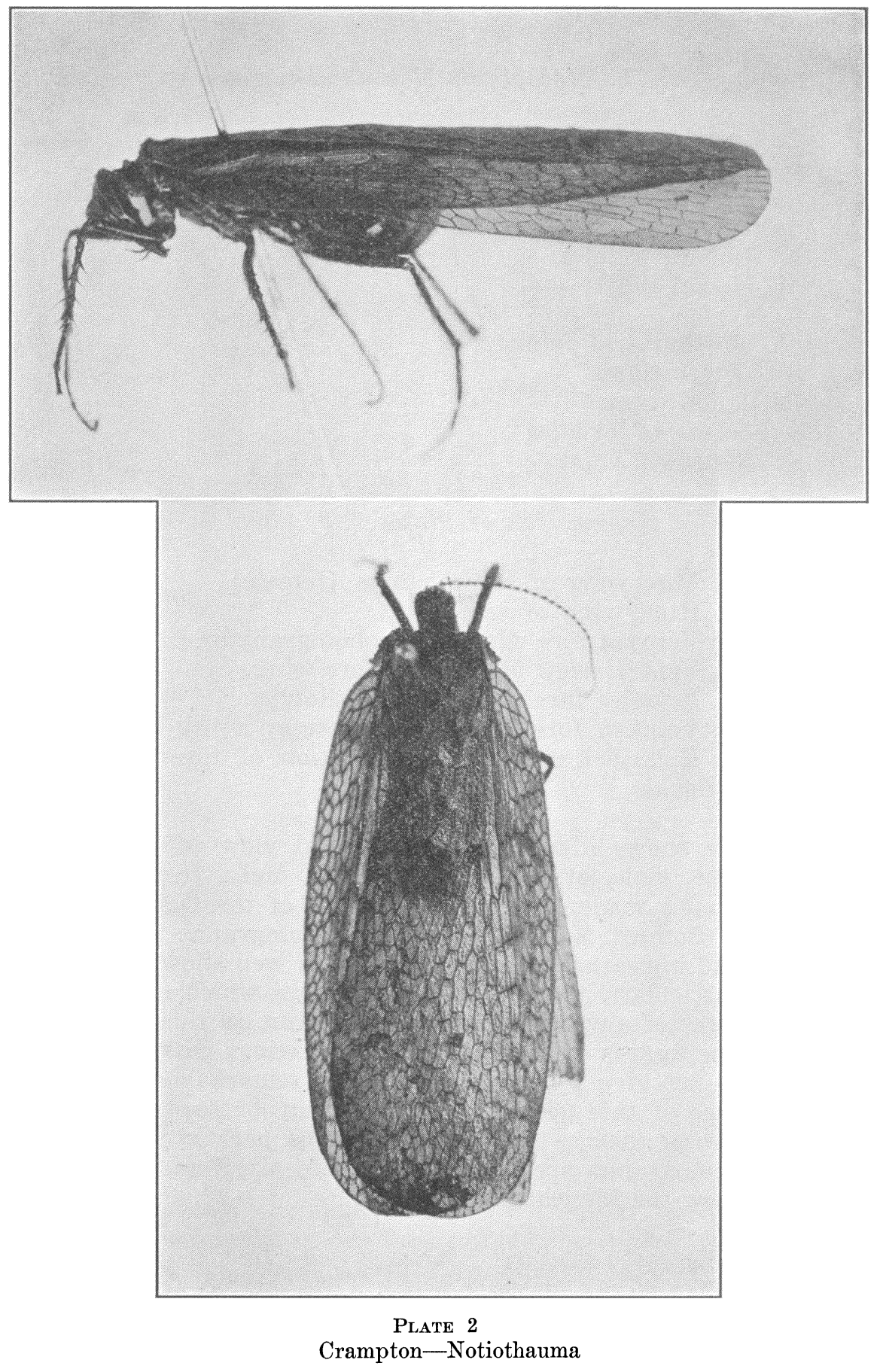




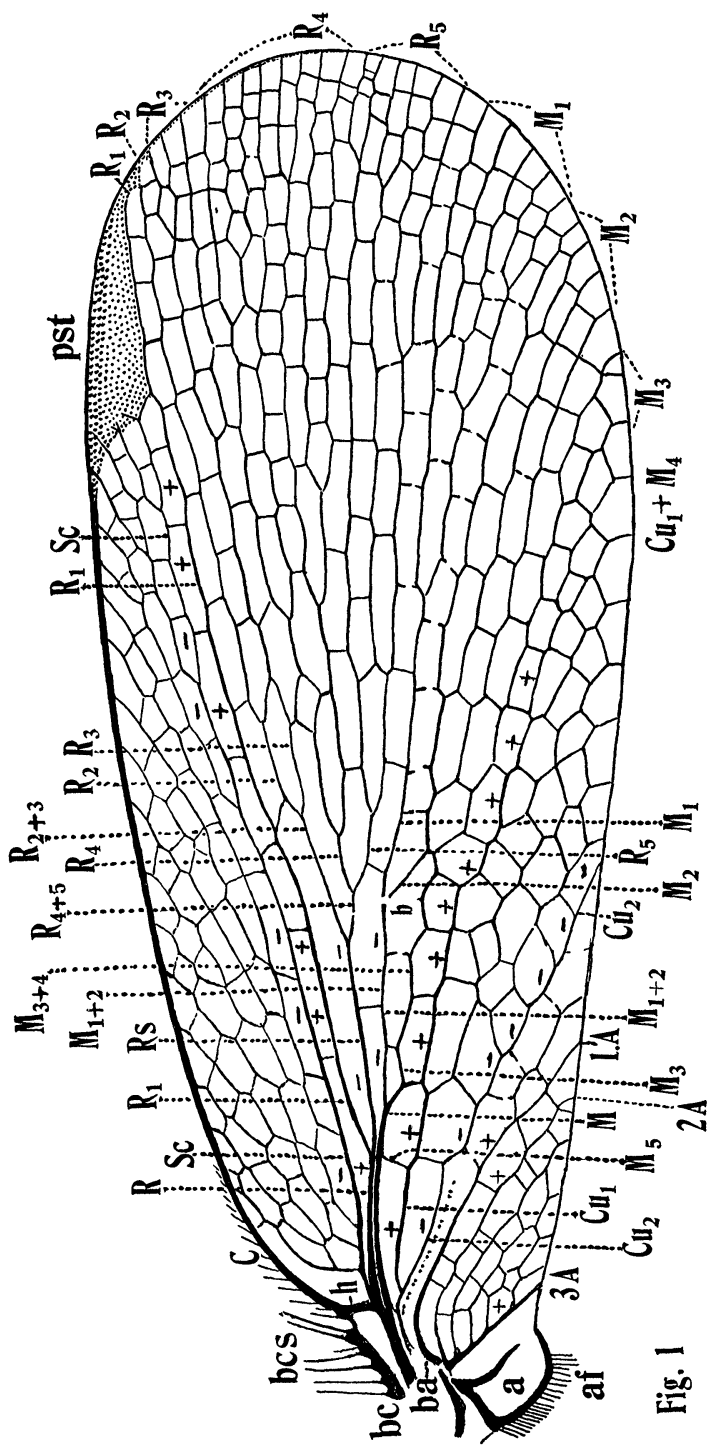

Plate 3

Crampton-Notiothauma 


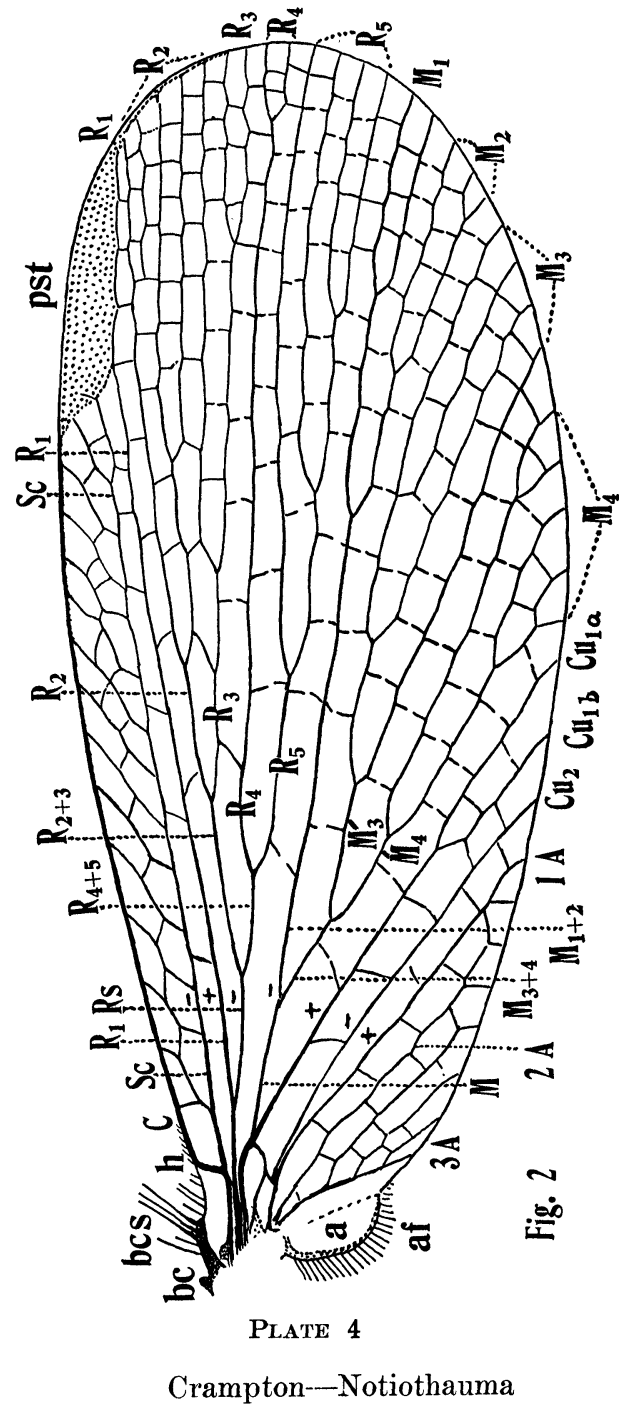




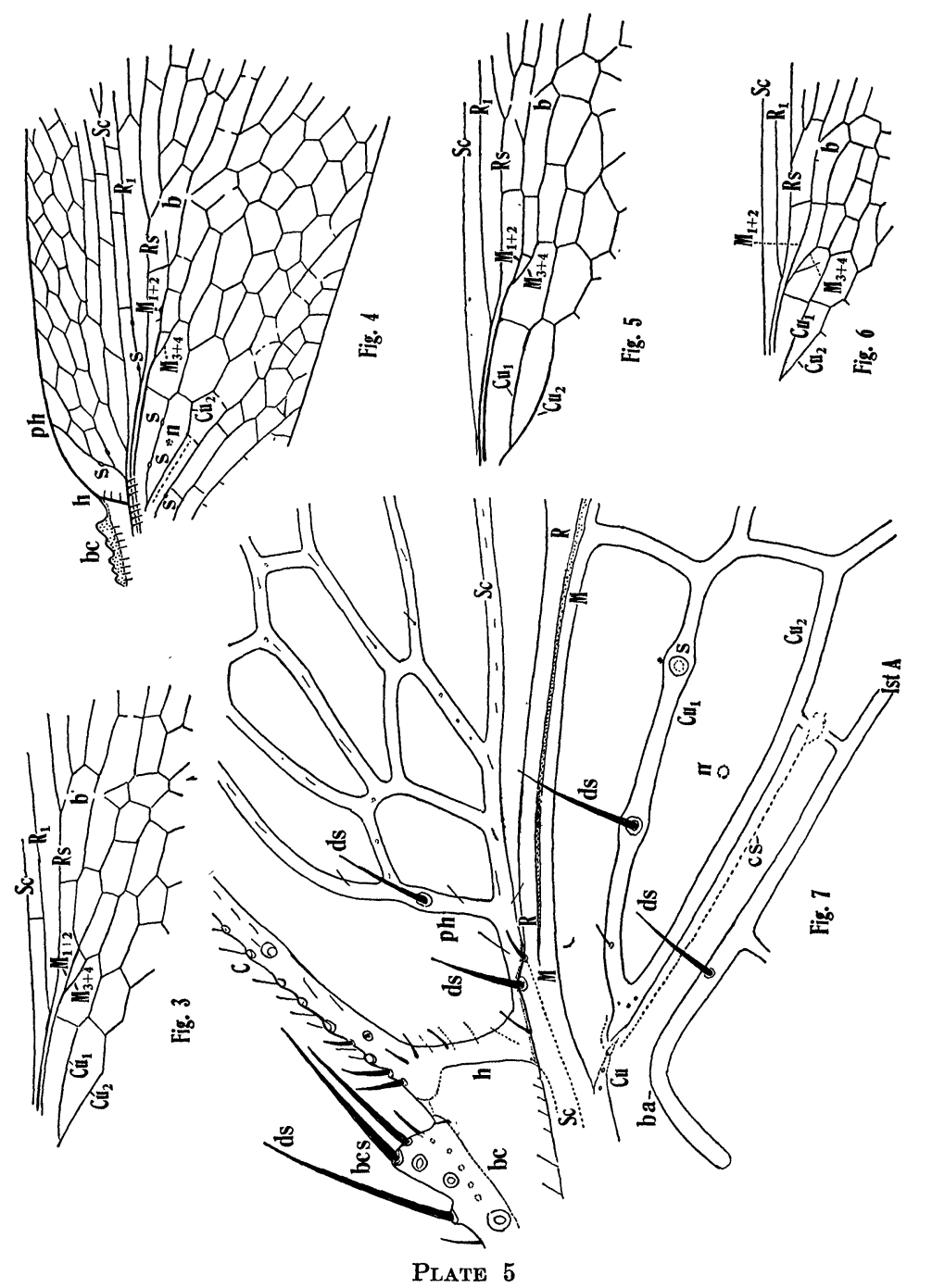

Crampton-Notiothauma 

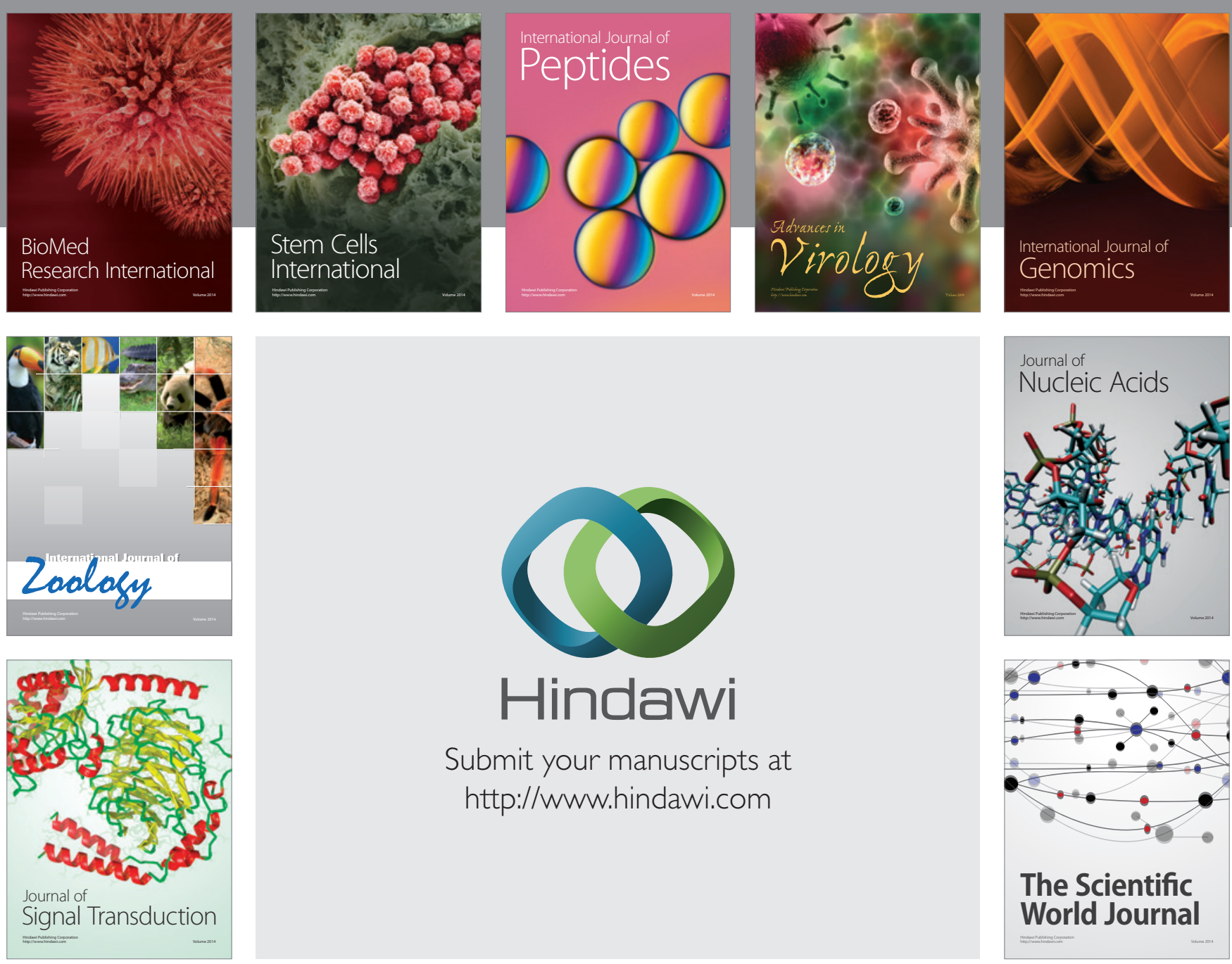

Submit your manuscripts at

http://www.hindawi.com
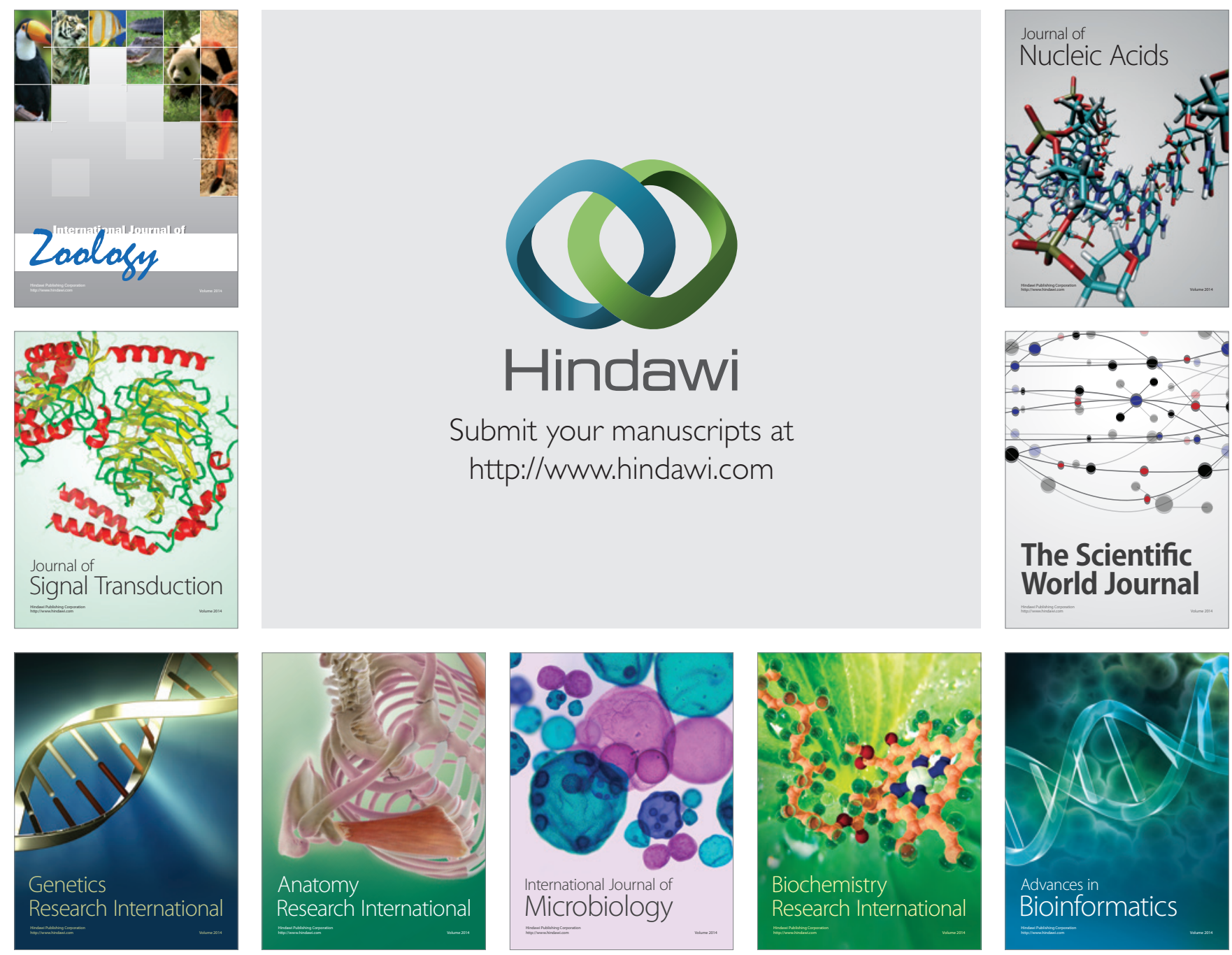

The Scientific World Journal
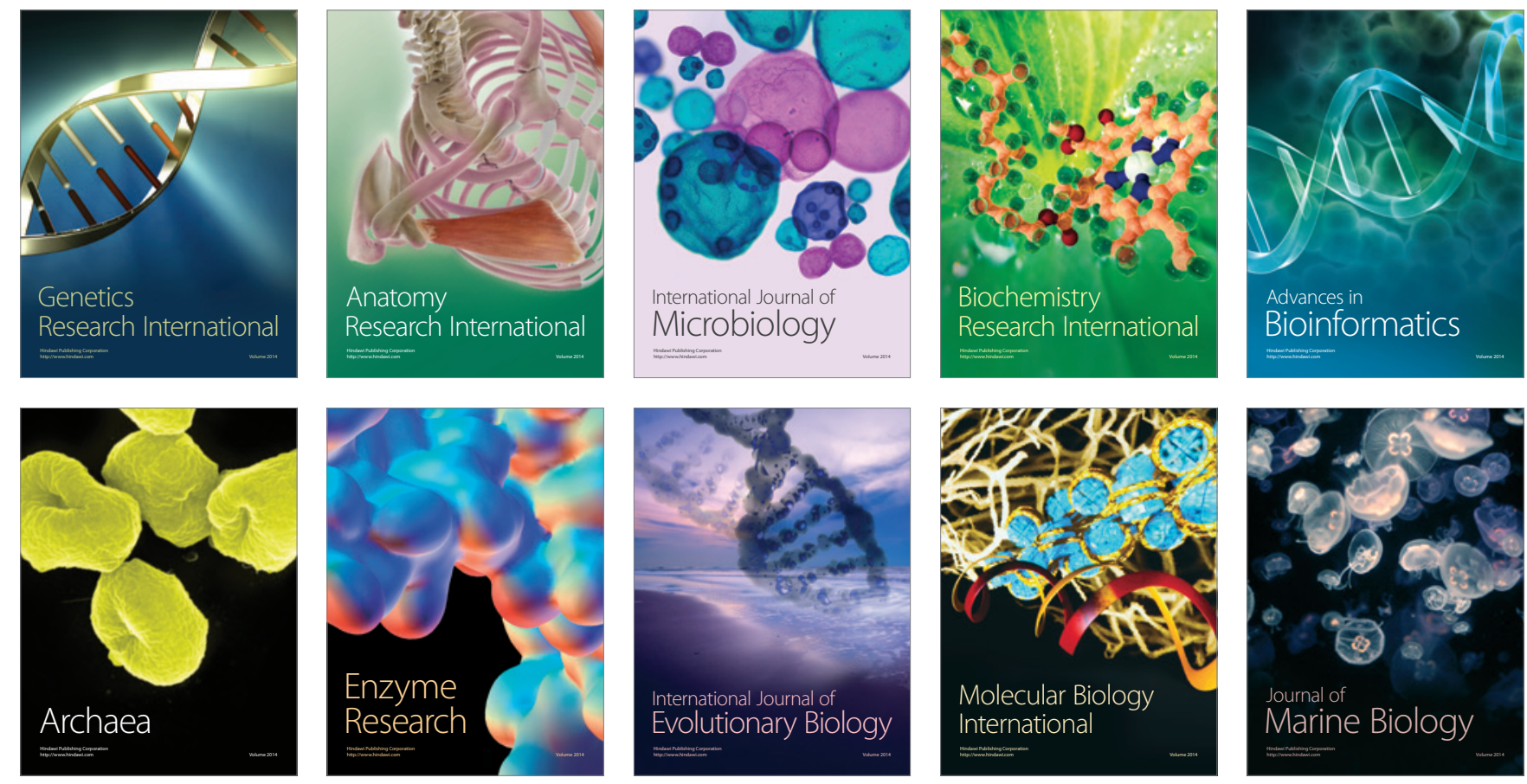